\title{
Dealing with Procrastination: The REBT Approach and a Demonstration Session
}

\section{Windy Dryden}

\section{Journal of Rational-Emotive \&} Cognitive-Behavior Therapy

\section{ISSN 0894-9085}

Volume 30

Number 4

J Rat-Emo Cognitive-Behav Ther (2012) 30:264-281

DOI 10.1007/s10942-012-0152-x

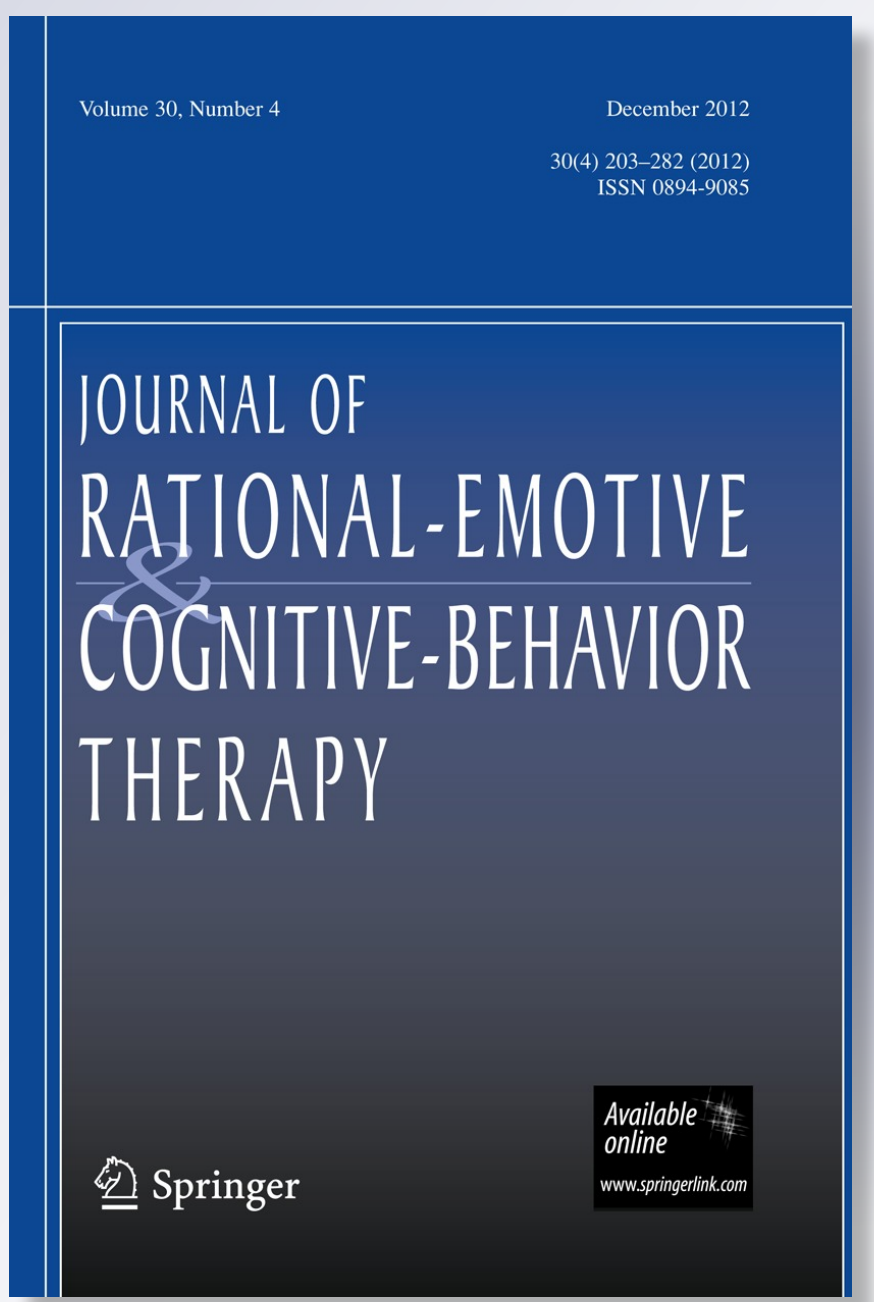

Springer 
Your article is protected by copyright and all rights are held exclusively by Springer Science+Business Media, LLC. This e-offprint is for personal use only and shall not be selfarchived in electronic repositories. If you wish to self-archive your work, please use the accepted author's version for posting to your own website or your institution's repository. You may further deposit the accepted author's version on a funder's repository at a funder's request, provided it is not made publicly available until 12 months after publication. 


\title{
Dealing with Procrastination: The REBT Approach and a Demonstration Session
}

\author{
Windy Dryden
}

Published online: 22 March 2012

(C) Springer Science+Business Media, LLC 2012

\begin{abstract}
In this article, the Rational Emotive Behavior Therapy (REBT) approach to procrastination is outlined and demonstrated using the transcript of a session conducted in the REBT "Master Therapists" DVD Series (Dryden in Overcoming Procrastination: Master Therapists DVD series, Albert Ellis Institute, New York, 2008). A commentary provides links between the demonstration session and the general approach. The session provides particular emphasis on helping procrastinating clients develop an attitude of discomfort tolerance and the need to focus on specific examples of procrastination and the specific rational beliefs that must be acted on in order to replace procrastination with task engagement.
\end{abstract}

Keywords Procrastination · REBT $\cdot$ Therapy demonstration

\section{The REBT Conceptualisation of Procrastination}

When people procrastinate, they put off doing a task that is in their best interest to do at a time when it is in their best interest to do it. The task and their best interest are judged by the people themselves rather than by any therapist or other interested person. In REBT, procrastination is seen as avoidant behavior at " $\mathrm{C}$ " in the "ABC" framework (Dryden 2000). What makes procrastination difficult to assess is that people do not often encounter the "A" or the emotional " $\mathrm{C}$ " due to procrastinating avoidance. Thus, it is typical when attempting to assess a person's procrastination problem that he ${ }^{1}$ quite often does not know what he is avoiding or what his major emotion at "C" would be if he actually encountered what he is avoiding.

\footnotetext{
1 In this paper, the therapist is female and the client is male.

W. Dryden $(\bowtie)$

PACE, Goldsmiths University of London, New Cross, London SE14 6NW, UK

e-mail: windy@thedrydens.clara.net
} 
It follows, therefore, that when assessing a person's procrastination problem, the therapist needs to help the client to imagine encountering the " $\mathrm{A}$ " that he is avoiding and to predict the major emotional " $\mathrm{C}$ " he would experience if he actually encountered the "A." When this approach is taken, it emerges that people who procrastinate would experience the full range of unhealthy negative emotions if they allowed themselves to encounter their "A's" rather than avoiding them. In particular, people who procrastinate would experience anxiety, depression, unhealthy anger and shame, if they encountered the "A"s that they typically avoid. If therapists are successful at identifying such unhealthy emotions, these emotions suggest inferential themes at "A" that are present in specific examples of procrastination (Dryden 2009a). Alternatively if therapists are successful at identifying the inferential theme present in these specific examples, then these themes suggest the unhealthy negative emotions that the person would experience if he encountered rather than avoided his "A" (Dryden 2009a).

Thus, when a person anticipates experiencing anxiety if he encountered rather than avoided his " $\mathrm{A}$ ", then the major theme present in the " $\mathrm{A}$ " would be threat, either to his self-esteem or broadly to his sense of comfort (Ellis 1979, 1980). When a person anticipates experiencing depression, then the major theme present in the "A" would be failure or some loss within the person's personal domain (Beck 1976). When a person anticipates experiencing unhealthy anger then the major theme present in the "A" would be that another person or state of affairs is curtailing the person's sense of freedom (Dryden 1996). Finally, when the person anticipates experiencing shame, then the major theme present in the " $\mathrm{A}$ " would be a major falling short of the person's ideal with an accompanying sense that others would look down on him (Dryden 1997).

Perhaps the main distinctive feature of REBT is the position it takes on the role of beliefs in psychological disturbance and health (Dryden 2009b). REBT argues that people do not procrastinate because they anticipate encountering threat, failure, curtailment of freedom and a significant fall from grace. Rather, they procrastinate because they hold rigid and extreme beliefs about these anticipated "A"s. These rigid beliefs often take the form of absolute musts, shoulds, got-to's and have to's and the extreme beliefs that are often derived from this rigid core take the form of awfulising beliefs, discomfort intolerance beliefs and depreciation beliefs relating to self, others or life conditions (Dryden 2009b).

People who procrastinate tend to adhere to a philosophy of low frustration tolerance (Ellis and Knaus 1977; Harrington 2005) and this is manifest in two major ways. First, they tend to avoid experiencing discomfort, particularly associated with the tasks that they do not want to do, but which is in their own judged best interests to do. Here, such people demand either that they must not experience discomfort or that they must only experience comfort. Second, they tend to be intolerant of experiencing emotional disturbance (Dryden 1999), and rather than experiencing such disturbance and working it through, they often choose to procrastinate and thereby avoid experiencing the disturbance. They do this because they demand that they must not experience disturbance or that they must only experience good feelings.

As with other emotional and behavioural problems, people who procrastinate then tend to focus on their procrastinating behavior and disturb themselves for 
procrastinating. While generally this is a legitimate target for intervention in REBT, it is important for the therapist to bear in mind one point. If she tackles this secondary problem first, then she may, unwittingly, reinforce the client's procrastination by putting off dealing with this primary problem in favour of dealing with the secondary problem.

\section{The REBT Treatment of Procrastination}

REBT therapists tend to deal with procrastination as they would with any other emotional or behavioural problem. Thus, she would begin with specific examples of the problem. However, as stated earlier, what makes dealing with procrastination particularly problematic is that the client does not get to encounter his " $\mathrm{A}$ " and therefore does not actually experience emotional disturbance at " $\mathrm{C}$ ". Consequently, having taken a specific instance of procrastination, the therapist needs to encourage the client to imagine staying with the task and thus to predict what emotion he would experience if he did not procrastinate. Taking this approach will also help the client and therapist to assess more accurately the client's "A". With "A" and the emotional " $C$ " assessed, it is fairly easy to assess the client's "B", since REBT theory states that a rigid belief and one or more extreme beliefs will underpin the person's procrastination. Formulation of the client's rational alternative beliefs is very important before any homework assignments are negotiated for without such alternatives, the client will find it only too easy to go back to his irrational beliefs since people do not live in a belief vacuum.

As in dealing with other problems, it is important to negotiate such homework assignments with clients. These should specify the task to be done, the time the client will start the task and, if necessary, where the task will be done. As will be seen in my session with Monty (below), for example, I negotiated with him that he would begin his task at a specific time (i.e., 3 p.m.) so that he would know he was procrastinating if by 3.01 p.m. he had not begun work on the selected task.

While eventually the therapist needs to help the client identify and work with more general core irrational beliefs, this general level of work should not be done until the client has demonstrated progress in acting on specific rational beliefs which result in task engagement rather than procrastination. People who procrastinate tend to be vague and abstract (e.g., McCrea et al. 2008) and need plenty of help dealing with specific examples of their problem before both therapist and client move to a more general level (Dryden 2009c).

People who have a chronic problem with procrastination tend to develop a number of rationalisations to deny to themselves and/or to others that they are not procrastinating when, in truth, they are. It is important that the therapist helps the client to identify a list of such rationalisations and to respond constructively to them if the client is going to fully commit himself to dealing with his procrastination problem over time.

People who have a chronic problem with procrastination also develop a set of justifications to explain to themselves the usefulness of procrastination (e.g., Neenan 2008; Spada et al. 2006). Common justifications include: "I need to feel anxiety to 
get going and therefore I will wait until I feel anxious before engaging in the task"; "I need to feel anxiety to be creative and therefore I will wait to feel anxious before engaging in the task"; "Even though I am not getting down to the task I am collecting the data I need to do the task. The longer I put off getting down to the task, the more data I will collect and the better I will do the task." As with rationalisations, it is important that the therapist helps the client to identify a list of such justifications and to respond constructively to them if the client is again going to fully commit himself to dealing with his procrastination problem in the longer term.

\section{The Demonstration Session}

The following transcript is of a session that I conducted in the REBT "Master Therapists DVD Series"2 (Dryden 2008). The client was an actor but was asked to present a real problem that he had and that he wanted help with. In what follows, I provide a commentary on my interventions and provide a link between theory and practice.

Windy Hello, Monty, thank you for coming in today. What problem would you like to present today?

Monty Er, procrastination, very long term and sometimes large scale.

Windy How do you define procrastination to yourself?

Monty Well, it's putting off things that... putting off the thing, and this is just sort of putting off critical things, it's a sort of a total problem, putting off things till the last minute or past the last minute that I have plenty of time to take care of that leads me into being like chronically late for things, chronically like stressing out about something that has been on the plate for a long time and, yeah, sort of like creating massive problems for myself that didn't have to exist.

Windy Yeah, I have a slightly different definition of procrastination. I see procrastination is putting off a task that is in your interest to do and putting it off beyond the time when it's in your interest to do it.

Monty I like that definition.

Windy Yeah?

Monty I think that sounds like what I'm talking about.

[I find it useful to agree a definition of procrastination with clients so that we have a shared view of the problem under consideration (Dryden 2006.)]

Windy So maybe take an example of... maybe a current example, maybe a typical example... of a task that you're putting off doing that it would be in your interest to do at a time when it would be in your interest to do it.

[As is typical in REBT I ask Monty for a specific example of his procrastination problem.]

\footnotetext{
2 The verbatim transcript appears here by kind permission of the Albert Ellis Institute.
} 
Monty Sure, like in the last $24 \mathrm{~h}$ there's two examples. One is I was supposed to have like the treatment of a script ready by the close of last week, there's a cast waiting on it, there's a pay cheque waiting on it...had a lot of time. The script is not finished, the treatment is not in and it was one of these things where I was moving up to start another project out of State recently and there were a few days before going up that I had kind of in my mind that I'm going to take care of this, it's going to be, you know, I should have enough hours to take care of it and it won't get...

Windy So it would be useful to focus on that particular episode...you mentioned two?

Monty Yeah, I was about to say the other one is a more general situation which sort of pops up continuously which is...

Windy Which would be more meaningful for you to focus on?

Monty Umm, yeah, actually now that I think about it, maybe the sort of the systemic as opposed to ...the script is sort of a specific anomalous thing while the other thing I was thinking about is something that kind of comes up.

Windy I still would like to take an example, if we go with the second one...

Monty Sure.

Windy ...I'll be asking you for an example.

[Monty provides two examples, so to strengthen the working alliance between us I ask him to choose one of the two (Bordin 1979). However, I stress the importance of Monty selecting a specific example of the problem whichever one he chooses.]

Monty Oh yeah, I've got this. It's most recent but it's part of a long and endless system.

Windy So do you want to go with the systemic one and take an example of that?

Monty Yeah. This is like... as an actor pretty much everything is... everything is time sensitive, like extremely time sensitive, and just recently, again, it's the most recent example is there is like a theatre company that I did some work with sort of by accident very recently and the Artistic Director and everything was like "great job", we need you to send in your head shot and all of the standard actor stuff, and... did not do it.

Windy It is still something that you're putting off?

Monty It's still something I'm putting off.

Windy Okay, so...

Monty It's like, I mean, I could have done it yesterday before coming here.

Windy Can I ask you then... if I were to ask you to define a time where you would agree with yourself, perhaps later on today, that you're going to sit down and do this task and yet you suspect that at that time you might put it off even having made that agreement with yourself, when might that be, would it be later on today?

Monty It would be like later on today.

Windy What time would you say?

Monty Like, you know, 3.00 p.m. 
[As I mentioned earlier, the therapist can maximise her impact with the client if she helps the client select a specific example of his problem that is imminent with a specified starting time. This helps both assessment and intervention and additionally provides the client with an immediate opportunity to deal constructively with his problem.]

Windy So let's take 3.00 p.m., let's take 3.00 p.m. and what I want to do is to try and get a flavour of how you procrastinate. So you have agreed with yourself, right...

Monty Yeah.

Windy ...you're going to do this task, and the task involves what, by the way?

Monty Yeah, getting to the computer, printing out a cover letter...

Windy Okay, so come three o'clock you have an agreement with yourself, you're going to sit down on this computer and get this cover letter done... and yet you are beginning to procrastinate. Can you imagine really focusing on that as a situation?

Monty Absolutely.

Windy Now, what do you think is going on at that point, what would it... what do you think might be going through your mind at that point that might lead you to break that agreement with yourself?

[My use of the general question "what do you think might be going on in your mind..." was deliberate in that I wanted to encourage Monty to look at his thinking as a relevant source of his procrastination. I will use REBT's specific formulation of procrastination later.]

Monty At some level there is a "ooh, I've got a little bit more time" so there are some other things that I could sneak in there. But there's also like a certain level of... I mean, it's, it's like a, like I don't want to have to do it at that time.

Windy You don't want to have to do it at that time, right.

Monty If that makes any sense...

Windy So the first one it sounds like you're beginning to kind of create a story which would...

Monty Justify why ...

Windy ...justify and that's what we call a rationalisation

Monty I'm good at those.

Windy You're good at those?

Monty Yeah

Windy Okay, and the other one, it sounds like you're beginning to experience some emotion which you are then moving away from. Would you say that would be correct?

[Monty's response indicates that he would rationalise not beginning the task ("I've got a little more time...") and that his procrastination would be motivated by an avoidance of feeling. I acknowledge both, but decide to assess the avoided "emotional C".] 
Monty Yeah.

Windy What do you think that emotion would be, that if you really allowed yourself to feel it that you might experience?

Monty It's like it's something like a, it's like a fear or something but it's...

Windy Fear?

Monty Yeah, it's the first word that comes to mind but it's...

Windy I'll tell you what the first word that came to my mind when I was listening to you and, listen, the point of this is that I may very well be wrong...

Monty Yeah.

Windy ...okay, and correct me if I'm wrong, but I kind of got a sense that you might be starting to feel, if you actually started to kind of do it, some kind of anger or resentment?

Monty Yeah, that's resentment towards it.

Windy Resentment?

Monty Yeah, absolutely.

Windy Right.

[Here, I asked the Monty what he would feel at " $C$ " if he allowed himself to stay with the task and not procrastinate and he says "fear". However, he says it in such a tentative way and his response seems to be at variance with what he said earlier (i.e. "I don't want to have to do it at that time") that I put forward an alternative emotion that more likely goes along with the sense of doing something that he does not want to do, i.e. "resentment" which Monty resonates with better than with "fear". At this point in the session I was looking for consistency between the language that he used and the feeling that he came up with and did not find such consistency. In putting forward my hypothesis about his emotional " $C$ ", I was careful to give him the opportunity to disconfirm my hypothesis by saying "correct me if I'm wrong".]

Windy Can you see that that resentment is somehow connected to your procrastination?

Monty Yeah.

Windy In what way would you say?

Monty I mean, it's a... I mean the worst part of this is having to slog through like endless amounts of outreach letters.

Windy Even though it's in your interest?

Monty Even though... I mean, because even though you know it's part of the... it's like that's not...like I don't think anybody gets into any of the creative fields, acting especially, like looking forward to do a whole lot of like outreach letters. I mean, even in spite of the fact that it's very clearly connected to the thing, I mean it's, yeah.

Windy You mentioned fear and I kind of noticed resentment. What do you think that in this episode that you're talking about, three o'clock, do you think the fear is the feeling that's going to stop you or the resentment?

Monty It's the resentment. 
Windy It's the resentment, okay. Who or what are you resentful towards? Is it a person, is it you, is it life conditions or... what's the object of your resentment?

[Having agreed that resentment is Monty's avoided emotional " $C$ ”, I begin the search for " $A$ ”.]

Monty That's a good question and the general result is that I get angry at myself for procrastinating that's the immediate after effect.

[This is an important choice point in the session. In response to my question concerning the object of his resentment (which would be his "A"), Monty responds by providing a secondary problem (anger at himself for procrastinating). While REBT encourages therapist to look for and work with such problems when these interfere with work on the primary problem, it would have been a mistake for me to have done this. As I pointed put earlier in the article, working on the secondary problem may be colluding with the client's own tendency to put off dealing with his primary procrastination problem. Also, by changing the focus at this point, I would be providing a poor role model for Monty who shifts focus both in the session and when there is a task to be done. This "shifting focus" is characteristic of those who have a chronic problem with procrastination and the therapist should endeavour to model "retaining the focus" for the client]

Windy Well, listen, if we went with that we'd be putting off dealing with the problem.

Monty (laughter) I know that.

Windy Sure.

Monty I mean, I think that the resentment is... I think it's definitely targeted at the, I don't know, the sort of the... the... I mean, not the specific people that I'm sending it to.

Windy It's not...?

Monty I mean, it's not like I think of like the Artistic Director who gave me the job the other day and was like sending in some extra work. It's not like specifically like how can you make me send this in, it's more like I just wish that wasn't the case that I have.

Windy Yeah.

Monty You know, I guess it's one of those things like you must do this and not only must I do this on this day, but you have to send in the head shots, the agents who aren't going to look at the thing, there's like a general level.

Windy So it kind of sounds that you're experiencing and, again, correct me if I' $m$ wrong, that somehow you are in a situation where your freedom is being curtailed.

Monty Definitely.

Windy Yeah?

Monty Definitely. 
Windy And would you say that you are angry about being put in that situation?

Monty Definitely.

[Here I have assessed the "A" which is I am being put in a situation that is curtain my Freedom.]

Windy So what do you do to prove that you are a free man at that time?

Monty I will like play video games.

Windy Right, okay. "I'm a free man"!

Monty And pretty much anything that I can find, at the lowest level. It's like when I'm at the computer and like Word is open, it can be like turn on some kind of -

Windy Yeah, so somehow, as long as you are kind of resentful about having your freedom curtailed and you are in a situation, you're going to prove to yourself that you are a free man, you are going to continue to procrastinate. Is that correct?

Monty That sounds spot on.

[Here I help Monty to see that from his perspective engaging in non-task behaviour helps him to restore his sense of freedom at that time, which he later calls "Monty time".]

Windy Okay, so what would you like to do instead?

Monty At?

Windy At three o'clock.

Monty Like today?

Windy Yeah.

Monty That's a good question, rather than writing this up?

Windy No, I mean...

Monty I would really like to get the letter out of the way...

Windy Yeah.

Monty ...that's, I mean, I'd like it to be gotten out of the way because that's the thing that like, I would really like to work with this company in the future and -

Windy Can I just feed back something to you about your language?

Monty Yeah, you don't like the way [laughs].

Windy Well, 'I'd like it to be gotten out of the way, rather than you doing it' [laughs]. Well, let's face it, you're not going to like to do it...

Monty No.

Windy ...but would it be more accurate to say well look, I'm going to choose to do it even though I don't want to do it because I want the outcome?

[In this section, I address the issue of goals with Monty and in particular, I give him feedback about his use of passive language: "I'd like it gotten out of the way". Instead, I emphasise the active, choice-based nature of him 
engaging with the task instead of procrastinating: "I'm going to choose to do it even though I don't want to do it because I want the outcome”.]

Monty Yeah.

Windy Okay. Now, in order to do that I guess we're going to have to help you to have a different attitude towards having your freedom curtailed. Because, you see, it sounds like, you know, I mean, I personally don't like having my freedom curtailed and yet I actually don't procrastinate that much because while we are grappling with the same issue here, I have an attitude that states that while I don't like having my freedom curtailed, I don't have to be exempt from that. I can actually choose to do something that I don't want to do to get the result I do want to want and in a funny sense I'm actually freer because in a strange sense it sounds like you have to do the video games to prove how free you are. And that's a bit of a dilemma because when you say you have to you are not free...

[There are a number of ways to make what REBT therapists call the " $B$ "- " $C$ " connection (Dryden and Branch 2008). I choose to do so here by engaging in therapist self-disclosure (Dryden 1990). Here I show Monty the relationship between my rational belief about curtailment of freedom and my nonprocrastinating behaviour. Additionally, I show Monty that by attempting to prove to himself that he is free by not doing what is in his interest to do, he is paradoxically not free. As his response below shows, this is a point with which he particularly resonates.]

Monty Yeah [laughs]. Ah bright light of day.

Windy Oh yeah bright light of day. Exactly.

Well, look, I reckon that there are three possible attitudes you can have towards having your freedom curtailed and let's have a look at them and let's have a look at the consequences of them and let's have a look at what's in your interest and let's have a look at... and then we can examine them.

The first one, and this is going to sound a bit strange but it's a theoretical possibility, but it does involve you lying to yourself, and that is the idea of what we call indifference and that would go something like this. "I don't care one way or the other whether my freedom is being curtailed or no. It is a matter of indifference to me."

Now, is that kind of something that appeals to you?

Monty I am not... I mean, it's definitely like it's an active, like I am gonna to do something that is my choice.

Windy I'm going to do something that is my choice because I have to prove what?

Monty I don't know if it's... I don't know if these are the thoughts of I've got to prove something. I don't know, maybe that is... it is definitely like, and this extends into a lot of different areas, but if there's definitely one thing it's like I just need to go to ground for a second...

Windy You need to go to ground? 
Monty Go to ground as in like I need to go and just have Monty time and like not... even though Monty time includes specifically not doing the things that I need to do.

Windy Monty time is in your mind, free time?

Monty It's my brain's sort of interpretation of like personal freedom.

Windy Yeah, so it's like a positive, yeah. So let's come back to the other two possible attitudes that you can have towards the curtailment of freedom is this, look, "I must not have my freedom curtailed, I really must not" or "I don't like it if my freedom is curtailed but, sadly and regretfully, that doesn't mean I'm exempt from that."

Now, which do you think you implicitly believe that leads to your resentment and procrastination?

[Here I more formally present the REBT model of resentment-based procrastination by outlining the three possible beliefs Monty could hold in this situation with respect to his "A" i.e. having his freedom curtailed: an indifference belief, a rigid demand (irrational belief) or a flexible, nondogmatic preference (rational belief). I then ask him which beliefs underpins his resentment/procrastination. This approach is known as the theory-driven approach to assessment in REBT (DiGiuseppe 1991a).]

Monty I mean, on an emotional level, definitely A.

Windy Where it is a must?

Monty Yeah.

Windy Okay.

Monty I understand that I really need to do these things but I feel that I should really, you know, take them on and do something...

Windy But as long as you believe, or act as if you believe, because in a way you never actually get to... you see, the thing about procrastination is it's basically a problem of avoidance, right, and therefore what you are avoiding is dealing with the issue of having your freedom curtailed.

You never get there. But, even though you never get there, you are reinforcing through your behaviour the idea that you have to have your freedom at that time. Your behaviour is strengthening the very attitude that is leading to your procrastination.

Monty Yeah, I'll buy that.

[Monty can see that is his irrational belief that underpins his procrastination. I capitalise on this by showing him that his procrastination also reinforces his irrational belief.]

Windy Yeah, okay. So the other alternative is to say well look, "I don't like having my freedom curtailed, but sadly and regretfully, I don't have to be immune from it or exempt from it and, therefore, I can choose to do what I don't want to do to get the results that I do want to have." 
And I put that to you, Monty, that that is true freedom. I put that to you that what you're doing is that you are a prisoner of your own must and musts don't give you freedom to manoeuvre. So when you think you're free, you're really a prisoner of your own musts. What do you think of that idea?

Monty I think it seems to hold water.

Windy Okay, so let's see if we can't rewind and put it into a situation that we will actually have at three o' clock, right? Typically speaking, what will happen today at three o'clock, your motivation would be to have this thing out of the way, right?

Monty Correct.

Windy So presumably, if a little fairy came along and did it for you, you would not object?

Monty Absolutely not. I spend a lot of time thinking that.

Windy Okay, so typically you are acting on the belief "oh, I'm being made to do something which I see is a curtailment of my freedom. I must not have this curtailment, I'm going to prove that I'm a free man, I'm going to have Monty time, I'm going to do what I want to do, prove I've got a free mind."

If you act out what you normally do, that would happen, is that correct?

Monty Yeah.

Windy Okay. So let's go back, let's really focus on this one. I'm going to play the must, right, and let's see if you can answer it back and see where we go.

Monty Okay.

Windy It's three o'clock and I'm... it's a bit like when you see Mickey Mouse and Donald Duck, I'm going to be the little Monty devil.

Monty Nice idea [laughs].

Windy Monty, listen, your freedom is being curtailed, you know, that mustn't happen to you, you need Monty time. Now, how are you going to respond to that?

Monty That Monty time will be richer in the future if I have Monty time on stage.

Windy Yeah, but "I must not really have this curtailment now, I've got to get rid of this negative thing right now."

Monty Bear with me, we'll take care of this and there will be Monty time later.

Windy Yeah, but, Monty, how are you going to... what attitude are you going to take to this curtailment of your freedom?

Monty I'd suck it up, I guess.

Windy Suck it up?

Monty Yeah.

Windy Which means what?

Monty Just ...

Windy I'm a poor British...

Monty Yeah, let's say that's Americanese for take it on the chin, keep on...

Windy Take it on the chin?

Monty Keep on going.

Windy What attitude towards the curtailment of freedom does that represent?

Monty Again, it's not a constructive attitude. 
Windy Isn't it?

Monty No.

Windy Okay, so ...

Monty It's not the choice and I guess the choice is, again, as you've said, it's just like this is the choice that...

Windy Yeah.

Monty ...like Monty time is creating the present and future for myself in which success in my craft which leads very obviously to personal happiness for myself and my loved ones is the priority as opposed to like immediate...

Windy But let's kind of really zero in on the attitude, lets have a look at those two attitudes... we are going to ditch the indifference belief.

Monty Yeah.

[In retrospect, I made the wrong decision here. Being keen to show viewers of the DVD a more emotive approach to disputing irrational beliefs, I assumed the role of devil's advocate. Here, I voice his irrational belief and encourage him to dispute it. I then backtrack and use a less emotive, but more focused approach to disputing which appears below (see DiGiuseppe 1991b). Here, you will see that I encourage Monty to keep his focus on his irrational and alternative rational belief at the same time and ask him to assess their empirical and pragmatic status. There are many ways of disputing beliefs, but I have found this approach to be particularly useful with many clients.]

Windy Let me go over them and have them side by side. The first one is saying "I... okay, my freedom is being curtailed, I must have freedom, I can't bear to have this curtailed."

Monty Right.

Windy As opposed to “Look, I don't like this but I don't have to be exempt from it, it's bearable, I can tolerate it and it's worth it."

Monty Yeah.

Windy Which of those beliefs is true and which is false? Is there a law which says that Monty must be free...?

Monty Free now, not so much. I mean, like, I don't know, it's at the point... at a certain level where it's like I remember having that time or something and maybe like it's a, yeah, and I don't know if I have ever read a law that says there has to be.

Windy No, exactly.

Monty Well, even if there was an unspoken law it's like -

Windy Actually, paradoxically, if there was a law you couldn't go against it. You'd be a prisoner of it.

Monty There it is.

Windy That's it and that's the ironic thing, because when you are a prisoner you're not free. You're not free to choose at the moment when your attitude is "I've got to get rid of this state of affairs right now where I am faced with doing something that I don't want to do even though it is in my interest to do it." 
So... but is it true, let's break it down, is it true that you would, at the time when your freedom is being curtailed is it true that you don't like that?

Monty Yeah.

Windy Okay, and is it also true "but there's no reason why I have to be exempt from that"?

Monty That's also true.

Windy Okay, so if you put that together it would be "Look, I don't like this but I don't have to be exempt from it, it's true and the idea that I must be exempt from it, I must get rid of it, I must not be, you know, have my freedom curtailed, that's not true."

Which of those two is healthier for Monty?

Monty I mean, it's definitely choosing to go non-exempt.

Windy Okay, which would you like to commit yourself to working on at three o'clock?

Monty Definitely the choice of not being exempt.

Windy Right, but now we're going to have to deal with one other issue which I think is in there and that is, when you make that choice you're going to be uncomfortable.

Monty Yeah.

Windy Do you know why?

Monty Because it's a change from the norm.

Windy Because there's freedom over here, there's videos over here which is Monty time and over there there's doing what you don't want to do even though it's in your interest. So you're actually going to feel uncomfortable because you've chosen to do what you don't want to do when there's an option of doing what you do want to do, right?

Monty Yeah

Windy Right, so, I guess, what would you typically say about that discomfort that might lead you to go to the video games, what attitude do you think you might be acting on, the idea that I've got to get rid of it or -

Monty I mean, absolutely. It's definitely the thing like I'll be working on the thing for real and be like man, this is like what a pain in the ass and then I will just temporarily just jump in here for a second so that I can feel like I'm having some of my time and then come back.

Windy Well, you see, you could still say this is a pain in the ass and still stick with it.

Monty Right.

Windy But in order to do that you have to see that again you have a rigid idea about lack of freedom because you're telling yourself, I'm hearing, I've got to get rid of this discomfort right now. Oh look, there's a very good way of doing it.

Monty Yeah, the click.

Windy The click, as opposed to, let's be honest, “I'm uncomfortable right now but I don't have to be free of that, I can tolerate the discomfort and see what happens", you see? 
So I would suggest perhaps a little homework assignment, we kind of suggest these things, and it would be at three o'clock, right, recognise that you made like a contract with yourself, right, recognise that when you sit down, you are going to have an urge, and it could be backed up by rationalisation, oh I've had a hard time, you know, things like that or even Professor Dryden is making me do it which I'm not, it's just a suggestion. So at that point you can either choose, and I'd suggest that you can rehearse this in your mind, "I don't like this curtailment feeling, I don't like this discomfort but I'm going to stick with it, it's in my interests. I don't have to be free right now in the way that I want freedom but I can have true freedom and choose to do something that I don't want to do when it's in my interest to do that because when I am going to the video games I'm not free because I believe I have to get rid of these other things."

[In the above part of the session, I am working with Monty on his attitude to discomfort. While people procrastinate for different reasons, most clients with a chronic procrastination problem have great difficulty engaging with a task when they feel uncomfortable. So, I bring up the topic of handling discomfort with Monty even though he has not explicitly mentioned it. I would go as far to say that if REBT therapists do not help their procrastinating clients to develop an attitude of discomfort tolerance then these clients will be particularly vulnerable to relapse.

It is worth noting again the specificity of the homework assignment that I negotiated with Monty. People who procrastinate need a clear marker for when they are procrastinating. So Monty knows that he is procrastinating if he has not begun work by 3 pm that afternoon. I have found that the more specific clients can be with themselves in terms of when they are going to do something and in which context, the more likely it is that they will do it. Also, I think that the sooner after the session clients agree to carry out a negotiated homework assignment, the more likely again they are to do it.]

Windy Now, can you imagine doing that?

Monty Yeah.

Windy Okay, now imagine you're doing that and imagine you've started to type, what happens then?

Monty I mean, even now just thinking about it, I can... like the images of like, man, but that game is right there.

Windy Okay.

Monty Immediately popping up.

Windy Okay, fine. That's fine. That's realistic and there's nothing that I can do or say that's going to stop you from having that thought pop up in your mind. Now, the question is, how are you going to respond to that thought?

Monty The response to the thought is yes, there's the thought but here's the thing. I mean, it's definitely true in personal experience that like when I succeed in pushing through like projects, be they late or whatever, it's always the 
feeling is a thousand times better than any, you know, temporary like stop gap.

Windy But it sounds like at that point, you see, having... it's almost like you back yourself into a corner and there's nowhere for you to go, that's what happens when you come at the last minute.

Monty Yeah.

[I have missed an opportunity to help Monty to develop and rehearse a rational belief concerning dealing with the immediate lure of the video game.]

Windy Do you also have a sense that, in a way, you work better under pressure at the last minute?

[Here I help Monty to identify a justification for continued procrastination. Note below how I suggest that he needs to test this hypothesis rather than assume that this is true.]

Monty Absolutely.

Windy Yeah.

Monty That's definitely ...

Windy How do you know that since you haven't tested that? [laughs]

Monty [laughs] Because that is generally the way I work.

Windy Must be good because I do it [laughs].

Monty I'm not sure what you mean [laughs].

Windy The point is you may well be right but you can experiment so the question is, let's just come back to that thought. Yes, there's a video game in here and the response towards that is "Yes, there is! But what am I going to choose to do?"

Monty Let's leave it there.

Windy "Yeah, okay, and I don't want to do it but I want..."

Monty I want it done.

Windy "I want it done and since..." I suppose you could get somebody to do it for you but that's not going to be...

Monty Not at this level.

Windy Not at this level. So is that a realistic image, that you are now at your desk. At what point do you think... is there a slight over the hump, that after a while once you get into it you'll get into the letter?

Monty Absolutely.

Windy Yeah.

Monty There's even like periods of time where I'm sort of easier on...

Windy You see, I often find that. It's really... it's like getting over the hump...

Monty Yeah.

Windy ...when you... first of all, you know, what happens typically in your case is you approach the task, as you approach in your mind, curtailment of freedom, I've got to get rid of that, I need Monty time, rationalisation, 
okay. You've got you through that and then you've started to do it and then there's still a part of your mind that says hey...

Monty Right.

Windy Yeah, there is, okay. Now, as you get into it the chances are you might still get those thoughts but the more you get into it they probably will lessen.

Monty Yeah.

[This is another error. It would have been better if I helped Monty to focus more on his implicit irrational belief about being tempted to engage in nontask behaviour and to help him develop a rational alternative belief. While the point I do actually make is a valid one - that if Monty starts work on his dissertation and continues to work on it no matter what thoughts crop up that encourage him to seek short-term satisfaction, then he will get into the task and continue to work on it - my focus is not sufficiently on Monty's beliefs. It would have been better for me to encourage Monty to first rehearse his rational belief i.e. "I may want to play that video game right now, but I don't have to do so" and then begin work on his agreed task while noticing but not engaging with the thoughts that tempt him to procrastinate.]

Windy Alright. Now, what about trying that... well, actively committing yourself to do that at three o'clock this afternoon?

Monty Absolutely.

Windy Okay, it would be very interesting to see what happens to you.

Monty Okay, thanks a lot.

Windy Thank you.

As this was a one-off demonstration session showing how an REBT therapist endeavours to help someone who has a procrastination problem, I do not know whether or not Monty carried out his agreed homework assignment. If this was regular therapy, I would have begun the following session by checking his assignment with him. If REBT therapists do not routinely check agreed homework assignments with clients in the following session, they communicate that these assignments are not really that important, an attitude detrimental to helping clients deal effectively with procrastination.

However, I think that this session does show REBT's distinctive approach to the assessment and treatment of procrastination as outlined in the early part of this paper.

\section{References}

Beck, A. T. (1976). Cognitive therapy and the emotional disorders. New York: International Universities Press.

Bordin, E. S. (1979). The generalizability of the psychoanalytic concept of the working alliance. Psychotherapy: Theory, Research and Practice, 16(3), 252-260.

DiGiuseppe, R. (1991a). The rational-emotive model of assessment. In M. Bernard (Ed.), Using rationalemotive therapy effectively (pp. 151-172). New York: Plenum. 
DiGiuseppe, R. (1991b). Comprehensive cognitive disputing in rational-emotive therapy. In M. Bernard (Ed.), Using rational-emotive therapy effectively (pp. 173-195). New York: Plenum.

Dryden, W. (1990). Self-disclosure in rational-emotive therapy. In G. Stricker \& M. N. Fisher (Eds.), Self-disclosure in the therapeutic relationship (pp. 61-74). New York: Plenum.

Dryden, W. (1996). Overcoming anger: When anger helps and when it hurts. London: Sheldon Press.

Dryden, W. (1997). Overcoming shame. London: Sheldon.

Dryden, W. (1999). Beyond LFT and discomfort disturbance: The case for the term "non-ego disturbance”. Journal of Rational-Emotive \& Cognitive-Behavior Therapy, 17(3), 165-200.

Dryden, W. (2000). Overcoming procrastination. London: Sheldon.

Dryden, W. (2006). Counselling in a nutshell. London: Sage.

Dryden, W. (2008). Overcoming procrastination: Master therapists DVD series. New York: Albert Ellis Institute.

Dryden, W. (2009a). Understanding emotional problems: The REBT perspective. Hove, East Sussex: Routledge.

Dryden, W. (2009b). Rational emotive behaviour therapy: Distinctive features. London: Routledge.

Dryden, W. (2009c). How to think and intervene like an REBT therapist. Hove, East Sussex: Routledge.

Dryden, W., \& Branch, R. (2008). The fundamentals of rational emotive behaviour therapy: A training handbook (2nd ed.). Chichester: Wiley.

Ellis, A. (1979). Discomfort anxiety: A new cognitive behavioral construct. Part I. Rational Living, 14(2), 3-8.

Ellis, A. (1980). Discomfort anxiety: A new cognitive behavioral construct. Part 2. Rational Living, 15(1), 25-30.

Ellis, A., \& Knaus, W. J. (1977). Overcoming procrastination. New York: Institute for Rational Living.

Harrington, N. (2005). It's too difficult! Frustration intolerance beliefs and procrastination. Personality and Individual Differences, 39, 873-883.

McCrea, S. M., Liberman, N., Trope, Y., \& Sherman, S. J. (2008). Construal level and procrastination. Psychological Science, 19, 1308-1314.

Neenan, M. (2008). Tackling procrastination: An REBT perspective for coaches. Journal of RationalEmotive \& Cognitive Behavior Therapy. Special issue on cognitive-behavioural coaching, 26(1), 53-62.

Spada, M. M., Hiou, K., \& Nikcevic, A. V. (2006). Metacognitions, emotions and procrastination. Journal of Cognitive Psychotherapy: An International Quarterly, 20, 319-326. 